Infrastructure Asset Management

Volume 1 Issue 4

Resilience assessment for geotechnical infrastructure assets

Shah, Jefferson and Hunt
Infrastructure Asset Management, 2014, 1(4), 95-104

http://dx.doi.org/10.1680/iasma.14.00007

Paper 1400007

Received 12/02/2014; accepted 18/07/2014

Keywords: geotechnical engineering/infrastructure planning/management

ICE Publishing: All rights reserved
,

\title{
Resilience assessment for geotechnical infrastructure assets
}

\section{Janvi Shah MSc}

PhD Researcher, School of Civil Engineering, University of Birmingham, Birmingham, UK; Geotechnical Engineer, Consulting, Amey Plc., Birmingham, UK

Ian Jefferson DIS, PhD, FGS

Reader in Geotechnical Engineering, Deputy Head of School (Teaching)

School of Civil Engineering, University of Birmingham, Birmingham, UK
Dexter Hunt MEng(Hons), PhD

Research Fellow, School of Civil Engineering, University of Birmingham, Birmingham, UK

There is a requirement for developing long-term strategic asset management plans that are resilient to future needs while ensuring efficient and robust service delivery. Developing such a holistic long-term approach will require adoption of robust, flexible and multifunctional solutions that not only suit the needs of the present but also are safe, secure and resilient to whatever the future may hold. This establishes a case for support to develop systems and frameworks that can enable asset owners, government organisation and other decision makers to make informed decisions for adopting such solutions. This paper presents a methodology for developing such a decision support framework, which tests the resilience of transportation design solutions in light of changing socio-economic, technological, environmental and political conditions into the future and enables strategic decision makers to evaluate the resilience potential of the proposed asset management solutions in light of these future conditions.

\section{Introduction}

Significant global investment in the infrastructure industry has been made in many countries around the globe. In the USA alone, US $\$ 1.75$ trillion was spent on the development and upkeep of the transportation infrastructure due to the constant and ever-growing demands and other natural forces that continue to cause deterioration of ageing transportation assets (FHWA, 2009). In Europe, Australasia and North America, this is exacerbated by reducing budgets. Many countries are specifically targeting their capital investments: energy, transportation, communications, flood management, water and waste infrastructure (see, e.g., HM Treasury, 2012). The Infrastructure Cost Review Report published by HM Treasury in December 2010 (HM Treasury, 2010b), estimated that from 2010 to 2015, between $£ 15$ billion and $£ 20$ billion per annum will be spent in the UK directly on infrastructure projects and programmes, including civil engineering works, that is, capacity enhancement, renewals, repairs and maintenance. From 2012 to 2013, the UK Highways Agency spent over $37 \%$ of its total departmental expenditure on the maintenance of strategic infrastructure networks (Highways Agency, 2013). Increased accountability of UK government bodies, for example, Resource Accounting and Budgeting, Whole of Government Accounting (Benton et al., 2005), has seen changes to the policy that requires improved infrastructure network performance through delivery of value for money and reliability (HM Treasury, 2011)

As such, there is overwhelming evidence for the need to develop innovative and sustainable ways to drive growth that is environmentally sensitive and in tune with societal needs (Bissell, 2010). Moreover, meeting the ever-increasing number of complex interdependencies in today's society requires technically sound, engineered and fit-for-purpose critical physical infrastructure components that operate efficiently throughout their life (ICE, 2009), providing both robust and resilient asset support (OECD, 2001). Minimising cost, time and risk measures within a systemwide asset management practice, while reducing the impact of political changes over project delivery, is not straightforward and requires long-term strategic planning, that is, a 25- to 30-year horizon (Armitt, 2013). However, it is a step towards better service delivery such that robust, flexible and multifunctional solutions that ensure safety, security and resilience both now and in the future are provided. Asset management removes the emphasis on each individual asset towards a more optimised approach that considers both the asset and the impacts on other surrounding assets of the same and differing nature. This establishes a further need to develop systems and frameworks that can enable asset owners, government organisations and other decision makers to make informed decisions for adopting such solutions. This paper presents a decision support framework that has been developed to test the resilience of geotechnical design solutions in the light of changing socio-economic, technological, environmental and political conditions in the future.

\section{Asset management}

\section{Definitions of asset management}

Various asset management guidance bodies and working groups, comprising experts from government authorities, asset owners and industries operating infrastructure assets both in the UK and globally, 
have given various definitions and best practice guidance on asset management. The definitions provided by several organisations, like PAS 55 (2008), OECD (2001), the County Surveyors Society (CSS) and the Institute of Asset Management, are closely aligned. In this paper, geotechnical asset management is defined as

'a systematic and organised approach for managing and maintaining physical geotechnical assets by optimum utilisation of resources throughout the whole life cycle of the asset base in order to provide the best value for money and ensure client satisfaction'.

\section{Developing a geotechnical asset management system}

Guidance for the development and implementation of an asset management system can be found in a number of guidance documents published in the UK and around the world, for example, OECD (2001), ISO 55000, ICE Manual of Asset Management (2011) and CSS (2004).

A generic asset management process begins with a clear idea of the goals and objectives of the organisation, which should be coherent with the policies and strategies laid out by the organisation for effectively managing their assets (in this case geotechnical). Subsequently, the condition of the assets must be identified prior to undertaking suitable gap analysis to compare the existing and expected performance of the asset. The next step is to undertake feasibility studies, which include undertaking adequate financial, risk and resource analysis in order to develop optimised solutions taking into account the whole life cycle of the asset and budget available. This is followed by delivering the service as per the asset owner's requirements while also monitoring the performance of the delivery.

\section{Geotechnical asset management - benefits} and challenges

The widely differing nature of the asset types found on any given infrastructure network is vast and complex. Understanding what constitutes geotechnical asset is fundamental to developing the nature, interdependence and criticality of the asset to the network as a whole. In this paper, the focus is on the geotechnical assets found on infrastructure networks, illustrating its use mainly on roads. Bernhardt et al. (2003) defines a list of geotechnical assets in which their function is ranked from exclusively geotechnical to minimally geotechnical, as shown in Table 1.
The main reason that sets geotechnical assets apart from other assets (and the reason why a specialised asset management framework is required) is the fact that all infrastructure assets are founded directly or indirectly on them. This means that ground-related failures have the potential to undermine the integrity of almost all construction projects (Clayton, 2000). This carries high risk because the predictability associated with man-made construction materials that are easy to modify and control do not apply to complex ground engineering conditions (including groundwater), whose properties vary with region and depth (Clayton, 2000). Geotechnical assets are not always visible to end users, and without a specialised geotechnical asset management system in place, there can be no direct acknowledgement of the valuable role that these assets play. In order to effectively maintain and manage any transportation infrastructure asset, it is of paramount importance to maintain and manage underlying geotechnical assets both effectively and robustly. For example, there is little merit in designing re-surfacing treatments for road pavements if the underlying sub-surface is weak and deteriorating, or remediating a cracking road carriageway if a supporting embankment has defects and is consequently slipping away, thereby disintegrating the support system for the carriageway. Geotechnical asset management is about identifying and putting in place remediating strategies where the underlying cause of failure is of a geotechnical nature.

\section{Preparing the case for Resilience Assessment Framework}

In this section, four pertinent questions related to the development and ultimately the adoption of the proposed resilient asset management framework are posed.

\section{Why do we have asset management systems?}

An asset management system, when tailored to the needs of the industry and adopted in a proactive manner, may provide several benefits to an infrastructure asset owner. The CSS 'Framework for Highway Asset Management' (CSS, 2004) suggests that a welldefined asset management system provides specific benefits, which include the following:

- reduced life cycle costs

- defined level of service

\begin{tabular}{|c|c|c|}
\hline Asset type & Asset function category & Purpose \\
\hline Embankments and slopes & Exclusively geotechnical & To provide gradual changes in vertical alignment \\
\hline $\begin{array}{l}\text { Tunnels and earth retaining } \\
\text { structures }\end{array}$ & Partially geotechnical & $\begin{array}{l}\text { To retain earthen materials so that highway can be } \\
\text { constructed in restricted right-of-way }\end{array}$ \\
\hline Culverts and drainage channels & & To provide control of surface waters \\
\hline Foundations & & To transmit structural loads to supporting ground \\
\hline Pavement subgrade & Minimally geotechnical & To serve as foundation for pavement \\
\hline
\end{tabular}

Table 1. List of geotechnical assets (reproduced from Bernhardt et al., 2003, with permission from ASCE) 
- ability to track performance

- improved transparency in decision making

- predicting consequences of funding decision

- decreased financial, operational and legal risk

- ability to discharge to financial reporting responsibilities and statutory valuation

The ICE Manual of Highway Design and Management 2011 (Walsh, 2011) highlights that asset management is something that engineers do in their day-to-day jobs with their skill to determine the cost and the design life of an asset. A large proportion of asset management also includes developing a strategic link between the service delivery and customer expectations. The manual argues that asset management should also focus on optimising the asset management processes in light of future development in technology and innovation along with efficient service delivery based on cost, performance and risks. This highlights the need for an infrastructure network to deal with changing social demands, environmental changes, new policies and growing technology and innovation. These form key elements within the proposed asset management framework.

\section{Does changing times mean changing measures?}

World population is predicted to increase to $9 \cdot 6$ billion by 2050 (United Nations, 2013), which will undoubtedly increase the demand for all types of infrastructure. As such, it becomes all the more important to effectively and efficiently manage infrastructure assets, not least because of the complex interdependencies that now exist. We now live in a world where failure of one asset may directly (or indirectly) lead to the failure (or breakdown) of a set of surrounding assets, which may ultimately lead to the failure of an entire section of the network. Hudson et al. (2012) argue that resilience of an asset can rarely (and should never) be considered in isolation; it is usually a part of an entire network and surrounding external environment. Hence, interaction between assets is a key element that cannot be neglected when designing resilience. With growing concerns related to increasing demands combined with reducing budgets (for maintaining and operating the geotechnical assets) in an uncertain future, there is a need to develop robust asset management systems, where vulnerabilities can be explored and prepared for. Hence, it is vital to determine whether the given asset management systems and practices (including design solutions provided today) for the remediation, maintenance and upkeep of geotechnical assets are applicable and fit for purpose within a range of future conditions (FCs).

This argument is strengthened when we consider that the infrastructure industry has been developed over many centuries and what is developed and built today will provide a legacy that lasts for many centuries to come. Notwithstanding this, we cannot forget that many (current) infrastructure assets are still in use, despite rapid changes in demographics, leading to changes in usage (sometimes beyond design parameters) and operational purpose (Boyko et al., 2012). This does not necessarily mean that the sustainable and technically efficient design solutions provided today will guarantee sustainability and resilience over their intended design lives. For example, a parallel might be drawn between the current state of the housing industry and the future of infrastructure industry considering the impact of recent 'changing times' on the condition of (and requirements for) the infrastructure network(s). Various housing developments in the UK and USA, which were designed to meet the limitations of the former housing conditions, have been made redundant before the end of their design life, with some demolished or re-developed due to the change in usage and requirement of urbanisation (Bullock, 2002; Wolfe, 1981). Therefore, it is not surprising that Boyko et al. (2012) argue that designing and developing solutions now in what we presume to be a sustainable and robust way for the future, even while carefully avoiding the errors made in the past (i.e. using hindsight in foresight), do not necessarily guarantee that the longterm resilience of the environment is achieved. So knowing what the future holds and how do we prepare for it will always be a question to which the most likely answer is 'it depends'. The asset management framework presented here provides a methodology by which we can begin to think beyond the traditional and explore beyond what we know now. This is key to this methodological approach.

\section{Do we need long-term policies and investment?}

In order to address the changing conditions facing the transportation industry, long-term planning and policy making is essential for effective asset management. Asset management strategies and policies prepared and adopted by various asset owners in the UK (e.g. Highways Agency, Network Rail and Local Authorities) have in the past typically tended to be devised for the short-term period (i.e. 5 years) and are directly linked to the nature of funding cycles and their associated influence from political changes. However, to date, there is limited work done through asset assessment frameworks for checking the robustness of these decisions over medium to long term (i.e. beyond 5 years). As such, there is a need to consider how the decisions made today, based on these shortterm strategies and policies, will affect the geotechnical assets of the future, say in 20 or 50 years. It is proposed that the Resilience Assessment Framework (RAF) system presented here moves us in the right direction to take cognisance of this.

The HM Treasury's National Infrastructure Plan 2010 (HM Treasury, 2010a) emphasises that globalisation, growing demands, climate change, interdependencies and obsolescence are the main future challenges that the infrastructure is faced with, and the UK infrastructure needs to keep pace with these in order to give high returns on investments, keep it running and continue driving economic growth and social development for the future that is both technologically enabled and customer focused. The document highlights the government's new approach towards infrastructure development, which aims to keep a coherent view of the long-term needs for UK infrastructure by managing interdependency, building resilience (see 'Embedding resilience in asset management') and promoting engineering innovation.

The key suggestions made at the ICE Infrastructure Conference on 'UK Transport - Engine for Growth' in 2013 included the development of a national transport plan to clearly understand what is needed from the transportation infrastructure in the long 
term. It suggested the long-term planning will help address the issue of increasing demand and ageing assets. It also encouraged development of long-term decision-making frameworks that consider the changing future for the transportation network.

An independent report by the Management Consultancies Association (2013) recommended that the National Infrastructure Plan should define the purpose of infrastructure services and provide a clear long-term vision of the economic and service environment desired for the UK. It also recommended that the UK government should create an independent office for infrastructure, which could produce national infrastructure plans addressing a time horizon well beyond the 4 or 5 years of political cycle and advise on projects that the government should take forward to fulfil its objectives by discussing the interactions between the project costs, timeframes and funding models.

\section{Embedding resilience in asset management}

Changing times and robust long-term policies and investment require that we build 'resilience' into our systems and strategies. In so doing, we can take account of infrastructure vulnerabilities, natural and man-made threats, changing demands, changing demographics, urbanisation, climate change and limited resources. Resilience, for the purpose of this paper, is defined as continued performance under changing conditions. Resilience in the infrastructure industry implies that the network (road, rail, utilities, water telecommunications etc.) is up and running, even if not in its best shape, but continues to perform for its intended purpose even in harsh and unpredictable conditions that it may be exposed to at any given time.

One of the prime lessons learnt from Hurricane Sandy in the USA in 2012 was that we need to design both redundancy and flexibility into all infrastructure systems in order to create resilience (Lee, 2012). Lee (2012) highlighted that out of such natural disasters comes the opportunity to develop adaptive strategies for the future. Similarly, a number of recent events in the UK demonstrated the vulnerability of transportation networks and how this can cause substantial disruption across the whole country. For example, the unusually low temperatures in 2010, the high flood levels in 2007 and the eruption of the Eyjafjallajökull volcano in Iceland in 2010 exposed the vulnerability in the UK's national infrastructure (in particular airlines) to rapid breakdown and, to some extent, failure. The UK Cabinet Office (2011) highlighted that these events not only caused inconvenience to the public but also incurred financial losses in the form of lost revenues, reputational damage and contractual fines and potential for legal action. For example, the 2007 floods alone cost the UK economy over $£ 4$ billion, and the damage specifically to critical infrastructure was valued at about $£ 674$ million. This also reinforces the critical need for organisations to manage and mitigate 'risks' and embed 'resilience' into their business processes (UK Cabinet Office, 2011).

Hudson et al. (2012) highlighted the need to engineer resilient infrastructure by exploring various examples of natural and manmade threats, including the fire explosion on the M1 and M4 motorways in the UK in 2011, caused by human negligence, that closed major arterial routes for days affecting the physical infrastructure and social activities. This was further illustrated by the nuclear power plant failure (caused by the devastating tsunami) in Japan in March 2011. This resulted in global consequences, with some nations abandoning nuclear power as a whole, leading to less diverse alternative source of energy.

It is further argued that there is a need to develop resilient infrastructure if a nation is to live a stable and buoyant life across the social, economic and environmental parameters both now and in the future (Hudson et al., 2012). Thus, enabling a nation to adequately develop methods (or design frameworks) for coping with the changes of an infrastructure base over (and sometimes beyond) its design life is paramount. This echoes the Pitt review, where it is stated that the driver for wider organisational resilience is the long-term commitment from stakeholders to mitigate risks as a part of a continuous improvement cycle (Cabinet Office, 2011). Hence, governance (policies) becomes a key driver in future proofing the infrastructure and making it resilient. Thus, the need to embed resilience into planning and design is justified, not only by considering the changes in use and growing age of the infrastructure, but also the requirement to invest well in infrastructure maintenance. There is a need also for a paradigm shift that places emphasis on designing in 'resilience' rather than in 'resistance', as is the case for many present solutions (Rogers et al., 2012). There is, however, also the issue of how to afford it.

In order to assess the solutions proposed and used in the real world today, it is essential to ensure that they are fit for purpose in the future and thus resilient to the challenges posed. To do this requires a sound decision support framework that can help facilitate translating the resilience strategies into tangible deliverables. This paper has described a step-wise methodology for assessing the resilience of geotechnical infrastructure assets within a nested step-wise model. Although the five-step framework was devised specifically for geotechnical assets on the railway and highway infrastructure, the concept and methodology can be adapted for any infrastructure asset.

As described in 'Does changing times mean changing measures?', geotechnical assets are the foundation of overall transportation networks, and hence are the starting point in making the infrastructure resilient. There is a need to create a RAF for geotechnical assets. Resilience can be embedded by ensuring the design solutions are fit for purpose to what the future holds. Hence, the RAF described in the next section considers changing social, economic, environmental, political and technological FCs against which the geotechnical design solutions are tested. In doing so, the framework contributes significantly towards meeting the overall resilience criteria.

\section{Resilience Assessment Framework}

An overarching study (see www.urban-futures.org) undertaken at the University of Birmingham (2008-2012) sought to test and examine today's sustainable solutions for urban redevelopment 
problems with regard to future scenarios for 2050 in such a way that robustness, flexibility and resilience were provided in the most cost-effective way possible (Lombardi et al., 2012). The study revealed that future scenarios have previously changed, are currently changing or have the power to change the world in which we live, and concluded that they can be categorised according to four archetypal visions (Hunt et al., 2012). These are Policy Reform (policy drives change), Market Forces (the market drives change), Sustainability Paradigm (people drive change) and Fortress World (instability and chaos drive change). The present study aims to further this thinking by answering the following key question:

'is the existing or proposed design solution for the geotechnical asset flexible and fit for purpose under such a set of changing conditions of the future?'

The work presented in this section highlights the overall philosophy of a RAF developed specifically for assessment of geotechnical asset management solutions. However, these principles can be adapted to suit any geotechnical asset base. This requires a wide range of user involvement including SMEs, client organisations, asset management organisations and engineers to define the specific aspects of the framework.

The following sections lay down the principles and methodology of development and the use of the newly developed 'RAF'.

\section{The what, how, when and who}

\section{The What}

The solutions provided today have a minimum design life of 60 years, but the conditions they may be subjected to are changing also, altering their role and intended purpose. This has required 'resilience' to be built into geotechnical infrastructure asset management in the best way possible. It is proposed that the methodology presented here provides a holistic framework in order for this to occur. This forms a key thread in the contribution to knowledge of this piece of research work. The purpose of the framework is to enable effective decision-making by selecting the most resilient solution (i.e. technically sound and fit for purpose) regardless of what the future may hold. Resilience assessment does not replace any of the existing assessment processes but rather is a form of acid test on the proposed solution that tests its applicability and flexibility under changing conditions, such as environmental, economic, social, political and technological.

\section{The How}

The assessment framework utilises a scoring matrix that provides a resilience score (RS) for each proposed design solution. The methodology is sufficiently flexible that a bespoke resilient assessment framework can be adopted for any asset specific to any project. The process for application is described fully in Section 4.2.

\section{The 'WHEN'}

The proposed tool can be adopted at the 'options analysis' stage for asset management systems (strategic) or engineering design (operational), where different options are evaluated and a feasibility analysis is undertaken to select the most technically sound, costeffective and sustainable solution.

\section{The Who}

Anyone can use the framework and the tool from the stakeholders to the client, project manager and designer. The benefits are seen across the project.

\section{A five-stage methodology}

The RAF uses five stages of analysis (Figure 1) within an overarching nested methodology that goes considerably beyond the bounds of existing frameworks (Stage 1 in Figure 1). This requires four additional stages of investigation, synthesis and application (with adequate iterative validation of key research outputs) that are appropriate for managing and maintaining geotechnical assets into the long-term future.

Stage 1 - Identify solution: This forms the basis of any existing asset management scheme, where a solution is proposed based on the condition of the existing asset (e.g. an option of remedial actions, long-term maintenance repair or replacement). In brief, this initial step identifies the goal and scope of the project (e.g. a road-widening improvement scheme, a slope failure remediation scheme) and detailed aspects of asset inspection and current/ previous condition. A gap analysis between the existing condition of the asset and the desired future level of service of the asset (in order to derive suitable design solutions) is proposed, and options for design solutions are identified.

Example: A deteriorating road link to the city is assessed in terms of its existing condition. A series of cost-assigned recommendations are made for its renewal, maintenance or replacement.

Stage 2 - Identifying critical success factors (CSFs): In this part of the nested model, CSFs that affect the performance, serviceability and stability requirements of the geotechnical asset base are identified (Table 2). They are drawn from an extensive review of the literature, industrial experience and case studies.

CSFs not shown include bio-diversity (CSF6), extreme climatic conditions (CSF7), asset interactions (CSF8), ease of maintenance and operation (CSF9), health and safety (CSF10), flexibility of use/multi-functionality (CSF11), obsolescence/ease of disposal (CSF12) and changes in standards and policy (CSF13). This list is not exhaustive, and the user can identify additional CSFs relevant to their project and asset type. In so doing, the framework can be enhanced on a case-by-case basis.

Example: In order for the transportation network to perform satisfactorily, the CSFs (1, 2, 3, 4, 5 and 14) of the geotechnical asset base are deemed critical.

Stage 3-Identifying FCs: In this step, conditions that characterise a plausible future that affects geotechnical assets (and more generally 


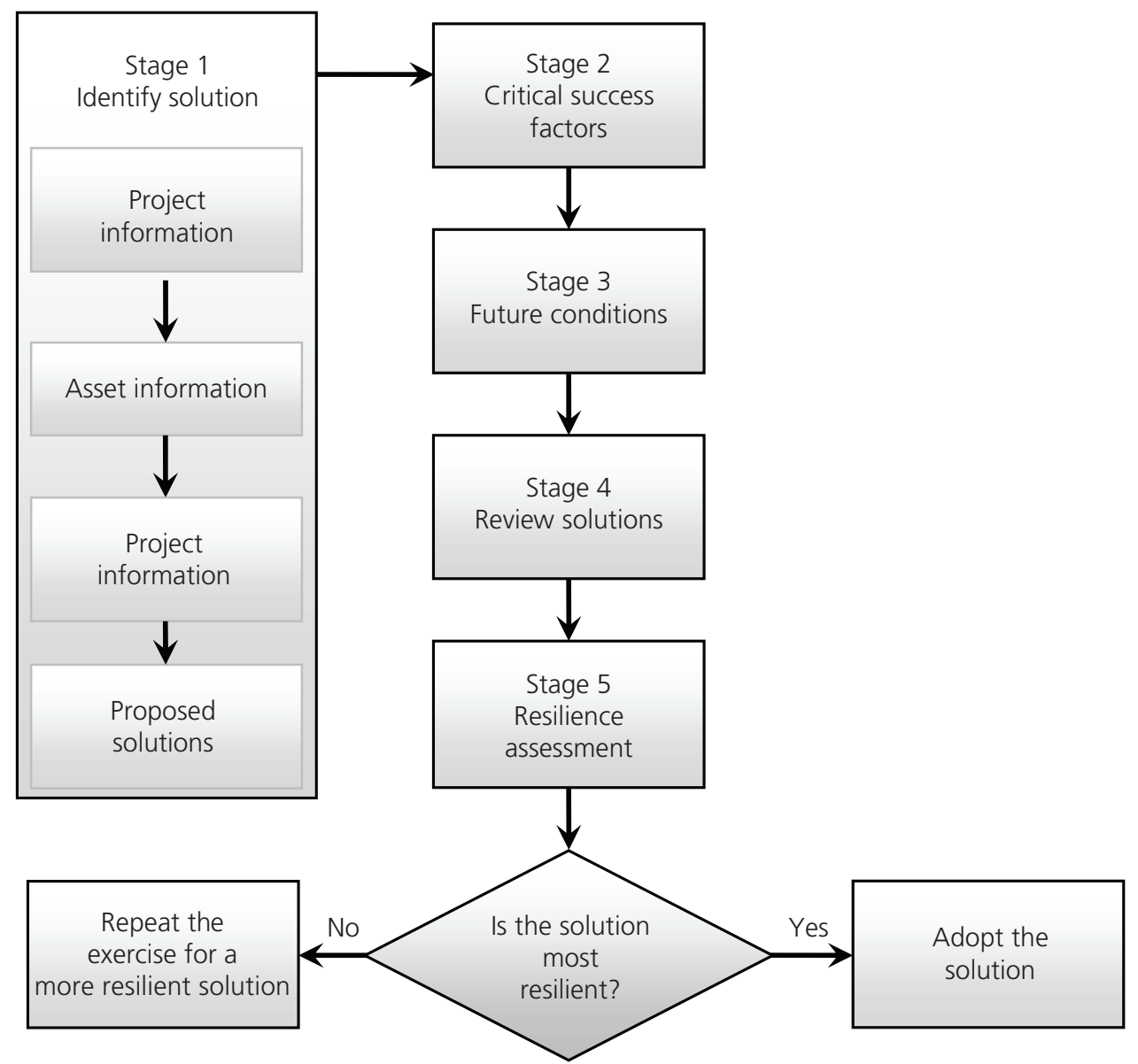

Figure 1. Resilience assessment methodology

\begin{tabular}{|c|c|c|}
\hline No. & CSFS & Description \\
\hline CSF1 & Flexibility to allow loading variation & $\begin{array}{l}\text { Proposed solution's flexibility and ability to adapt to the loading } \\
\text { variations (surcharge, change in use etc.), causing increased } \\
\text { demands and need for multi-functionality. }\end{array}$ \\
\hline CSF2 & Seepage characteristics & $\begin{array}{l}\text { Proposed solution's response to seepage conditions in terms } \\
\text { of nature of the material and its influence on reducing } \\
\text { groundwater and pore water pressure. }\end{array}$ \\
\hline CSF3 & Effect on drainage & $\begin{array}{l}\text { Proposed solutions response to effectively drain the slope in } \\
\text { the event of excessive precipitation and excessive storm water } \\
\text { drainage in order to regulate groundwater. }\end{array}$ \\
\hline CSF4 & Effect of pollution/contamination & $\begin{array}{l}\text { Effect of pollution and contamination due to triggering of } \\
\text { contamination pathways or live traffic and spillages etc. on the } \\
\text { solution and its applicability and fitness for purpose. }\end{array}$ \\
\hline CSF5 & Impact of erosion & Proposed solution response to erosion caused by water or wind. \\
\hline$\vdots$ & $\vdots$ & $\vdots$ \\
\hline CSF14 & Whole fife costing & $\begin{array}{l}\text { Overall optimum costs throughout the life cycle of the asset } \\
\text { right from material, transport, construction, maintenance and } \\
\text { disposal of the solution. }\end{array}$ \\
\hline
\end{tabular}

Table 2. Critical success factors 
the transportation and infrastructure industry) are identified. These include aspects encapsulated within the following seven drivers for change:

- FC1 - Demographics

- $\mathrm{FC} 2$ - Environmental

- FC3 - Social changes

- FC4 - Economic changes

- FC5 - Governance (policy drivers)

- FC6 - Technology/Innovation

- FC7 - Natural and man-made shocks

Example: A change in demographics occurs that affects the transportation network that connects to the city. This could be attributed to a change in population density of an area, urbanisation patterns and an overall impact of globalisation that has an effect on the trade and migration patterns.

Stage 4-Review of proposed remedial solution: In light of the implications highlighted from Stages 2 and 3, assessment is made of whether the solution is sufficiently flexible, fit-for-purpose and applicable both now and in the future, thus enabling engineers/users to undertake a sensitivity analysis of the different proposed design solutions.

Example: Geotechnical assets are likely to be affected by usage, need and level of service expected. An unforeseen increase in traffic density will put additional pressure on the network. This in turn triggers a change in use of the assets, resulting in an increased demand for multi-functionality and an increase in the need for efficient interaction between different assets on the network.

Similarly, a decrease in use for the network (perhaps due to emigration due to poor economic conditions or due to increased susceptibility to environmental hazards such as floods etc.) may mean the solution devised today may be over-engineered for the needs of the future.
The inter-relationship between the FC 'change in demographics' and the CSF 'flexibility to allow for loading variations' is deemed important in this example. A similar approach needs to be undertaken for determining the inter-relationships for all other FCs and (relevant) CSFs.

Stage 5 -Application of scoring and weightings: In this step, a multi-criteria decision (and sensitivity) analysis is developed for the proposed solution(s) with an intention to test their resilience. A scoring system is subsequently applied using an innovative matrix of FCs (Table 3(a)). In line with Table 2, only 6 of the 14 CSFs are included for clarity.

Firstly, the FCs receive a weighting $W$ based on the requirements of relevant outlined users (e.g. asset owners, government organisations and other clients), engineers, subject matter experts, asset management professionals and so on. Substantial stakeholder liaison is required in order to discuss the importance of FCs for the project, and depending on the priorities and requirements of these stakeholders, appropriate weightings can then be adopted.

Secondly, the asset design solution is assessed for each CSF in light of each relevant FC to see if an interrelationship exists. Unshaded cells represent the existence of an inter-relationship, and shaded cells represent a non-existent or non-relevant inter-relationship (Table 3(b)). A CSF score $\left(C_{\mathrm{x}}\right)$ is then calculated from Equation 1

\section{1. $C_{\mathrm{x}}=A / B$}

where $C_{\mathrm{x}}$ is the CSF score, with $\mathrm{x}$ as the column numbering within the matrix (e.g. $C_{1}$ in Table 3(a)), $A$ is the number of unshaded cells in each CSF column (e.g. for column CSF1, $A=6$ in Table 3(b)) and $B$ is the total number of unshaded CSF cells in all CSF columns (e.g. $B=26$ for Table $3(b)$ ).

\begin{tabular}{|c|c|c|c|c|c|c|c|c|}
\hline \multirow{3}{*}{ FC } & \multirow[t]{3}{*}{ Weighting $W$} & \multicolumn{6}{|c|}{ CSFs } & \multirow[t]{3}{*}{ RS } \\
\hline & & CSF1 & CSF2 & CSF3 & CSF4 & CSF5 & CSF14 & \\
\hline & & $C_{1}$ & $C_{2}$ & $C_{3}$ & $C_{4}$ & $C_{5}$ & $C_{14}$ & \\
\hline FC1 - Demographics & $W_{1}$ & $\mathrm{~S}_{11}$ & $\mathrm{~S}_{21}$ & $\mathrm{~S}_{31}$ & $\mathrm{~S}_{41}$ & $\mathrm{~S}_{51}$ & $\mathrm{~S}_{141}$ & $\mathrm{RS}_{1}$ \\
\hline FC2 - Environment & $W_{2}$ & $\mathrm{~S}_{12}$ & $\mathrm{~S}_{22}$ & $\mathrm{~S}_{32}$ & $\mathrm{~S}_{42}$ & $\mathrm{~S}_{52}$ & $\mathrm{~S}_{142}$ & $\mathrm{RS}_{2}$ \\
\hline FC3 - Social & $W_{3}$ & $\mathrm{~S}_{13}$ & $\mathrm{~S}_{23}$ & $\mathrm{~S}_{33}$ & $\mathrm{~S}_{43}$ & $\mathrm{~S}_{53}$ & $\mathrm{~S}_{143}$ & $\mathrm{RS}_{3}$ \\
\hline FC4 - Economics & $W_{4}$ & $\mathrm{~S}_{14}$ & $\mathrm{~S}_{24}$ & $\mathrm{~S}_{34}$ & $\mathrm{~S}_{44}$ & $\mathrm{~S}_{54}$ & $\mathrm{~S}_{144}$ & $\mathrm{RS}_{4}$ \\
\hline FC5 - Governance & $W_{5}$ & $\mathrm{~S}_{15}$ & $\mathrm{~S}_{25}$ & $\mathrm{~S}_{35}$ & $\mathrm{~S}_{45}$ & $\mathrm{~S}_{55}$ & $\mathrm{~S}_{145}$ & $\mathrm{RS}_{5}$ \\
\hline FC6 - Tech/Innovation & $W_{6}$ & $\mathrm{~S}_{16}$ & $\mathrm{~S}_{26}$ & $\mathrm{~S}_{36}$ & $\mathrm{~S}_{46}$ & $\mathrm{~S}_{56}$ & $\mathrm{~S}_{146}$ & $\mathrm{RS}_{6}$ \\
\hline FC7 - Shock events & $W_{7}$ & $S_{17}$ & $\mathrm{~S}_{27}$ & $\mathrm{~S}_{37}$ & $\mathrm{~S}_{47}$ & $\mathrm{~S}_{57}$ & $\begin{array}{c}\mathrm{S}_{147} \\
\text { Total RS }\end{array}$ & $\begin{array}{c}\mathrm{RS}_{7} \\
\mathrm{RS}_{\text {total }}\end{array}$ \\
\hline
\end{tabular}

Table 3(a). Innovative matrix of FCs for an asset design solution 


\begin{tabular}{|c|c|c|c|c|c|c|c|c|}
\hline \multirow[t]{2}{*}{$\mathrm{FC}$} & \multirow[t]{2}{*}{ Weighting $W$} & \multicolumn{6}{|c|}{ CSFs } & \multirow[t]{2}{*}{ RS } \\
\hline & & 0.250 & 0.083 & 0.125 & 0.208 & 0.167 & $0 \cdot 167$ & \\
\hline FC1 - Demographics & 10 & 3 & & & & & & $7 \cdot 5$ \\
\hline FC2 - Environment & 30 & 2 & & -2 & -3 & 2 & & $-1 \cdot 3$ \\
\hline FC3 - Social & 5 & 1 & & & & -1 & -3 & $-2 \cdot 1$ \\
\hline FC4 - Economics & 30 & 2 & & -2 & 1 & 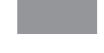 & -2 & $3 \cdot 8$ \\
\hline FC5 - Governance & 10 & -2 & 1 & 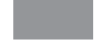 & 2 & 0 & 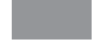 & 0.0 \\
\hline FC6 - Tech/Innovation & 20 & 3 & 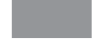 & $2 \cdot 3$ & -1 & 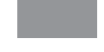 & 2 & $23 \cdot 3$ \\
\hline FC7 - Shock events & 5 & 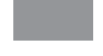 & 1 & 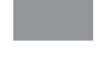 & 3 & 0 & 0 & 3.5 \\
\hline
\end{tabular}

Table 3(b). Example using innovative matrix of FCs for an asset design solution

For example, in Table 3(b), $C_{1}=6 / 24=0 \cdot 25$.

Thirdly, solution scores $\left(\mathrm{S}_{\mathrm{xy}}\right)$ are assigned within unshaded cells based on the existence of an interrelationship within the matrix (example scoring is given in Table 3(b) to illustrate the process), where $x$ and $y$ are used to define the intersection points within the matrix. Scores range from -3 (least resilience potential) to +3 (most resilience potential). Table 4 shows an example of a clearly defined scoring key used for the purpose of this study. Lastly, an RS is calculated for each row according to Equation 2

$$
\text { 2. } \mathrm{RS}_{\mathrm{y}}=W_{\mathrm{y}} \sum\left(C_{\mathrm{x}} \times \mathrm{S}_{\mathrm{xy}}\right)
$$

where $\mathrm{RS}_{\mathrm{y}}$ is the Resilience score, and $W_{\mathrm{y}}$ is the weighting (e.g. $W_{1}=30$ for FC2).

For example, in Table 3(b), $\mathrm{RS}_{2}=30 \times[(2 \times 0 \cdot 25)+(-2 \times 0 \cdot 125)+$ $(-3 \times 0 \cdot 208)+(2 \times 0 \cdot 167)]=-1 \cdot 3$.

\begin{tabular}{|c|c|}
\hline Score & Description \\
\hline+3 & Existing solution works with no change in design \\
\hline+2 & $\begin{array}{l}\text { Existing solution works with minor amendments } \\
\text { and marginal cost and time implications }\end{array}$ \\
\hline+1 & $\begin{array}{l}\text { Existing solution with room for improvement to } \\
\text { design with reasonable time and cost implications }\end{array}$ \\
\hline 0 & Neutral or not applicable \\
\hline-1 & $\begin{array}{l}\text { Existing solution requires design changes with } \\
\text { additional time and cost implications }\end{array}$ \\
\hline-2 & $\begin{array}{l}\text { Existing solution requires substantial design } \\
\text { amendments to its original form and surrounding } \\
\text { area with substantial time and cost implications }\end{array}$ \\
\hline-3 & $\begin{array}{l}\text { Existing solution does not work and requires } \\
\text { replacement with re-engineered solution have } \\
\text { major time and cost implications }\end{array}$ \\
\hline
\end{tabular}

Table 4. Example of a scoring key
Lastly, $\mathrm{RS}_{\text {total }}$ is found by summing all RSs in the column. In this example, these total $34 \cdot 7$.

Although the final output is in the form of a total RS, it is also possible to see in which FC the solution is most resilient (i.e. 'Technology/Innovation' in Table 3(b)) and in which it is least resilient (i.e. 'Social' in Table 3(b)).

Example: For a strategic network of roads connecting a city with foreseen increasing density, the road will be required to meet increased demands for traffic, which will put additional pressure on the network (and geotechnical asset).

For the critical factor 'flexibility to allow variation in loading' (CSF1), if the proposed solution is able to cope with changing loading patterns with minimal alteration and no changes to the design with the 'change in demographics' (FC1), then it is awarded a +3 (as assumed in Table 3(b)), suggesting it is a highly resilient solution for that FC. On the other hand, if the proposed solution was expected to be of no use under changing loading conditions to such an extent that the existing solution would have to be demolished and replaced, imposing additional time and cost implications, it would have been given a -3 .

\section{Discussion}

Resilience is defined as the continued performance under changing conditions. Typically, for geotechnical assets, these conditions are limited to areas that traditionally remain within the scope of geotechnical engineering (e.g. soil properties and loading). The RAF described within this paper caters for a much enhanced resilience assessment way beyond this narrow silo scope by taking into consideration much broader drivers of change (i.e. social, technological, environmental, political and economic) and in so doing provides a clearer understanding of how the solutions will perform in light of these changing conditions. In so doing, it helps make robust decision-making, whereby technically sound and fitfor-purpose solutions can be adopted whatever the future holds. The proposed RAF provides a robust platform to compare the resilience potential of a plethora of geotechnical asset solutions by providing an RS that can be used to compare and benchmark projects on a 
like-for-like basis. The purpose of the RAF more than fulfils its brief as a practicable methodology for undertaking measurable 'futurebased' sensitivity analyses so as to determine how resiliently the identified solution will perform far into the future. While there are tools and frameworks that already assist in undertaking effective asset management by efficiently analysing asset databases, there is no framework that enables a user to broadly assess the resilience of identified solutions. These existing tools are limited to finding technically sound and cost-effective solutions based on present conditions alone, whereas the RAF does all of this but then provides an extra filter through which these solutions can be hypothetically tested to see if they continue to perform in light of changing socioeconomic, governance, regulatory, technological and environmental conditions, which they may be subjected to throughout their design life. In this way, the proposed RAF contributes significantly to knowledge with respect to current and future geotechnical asset management protocols.

\section{Conclusion}

The concept of sustainability and resilience has gained significant importance in recent years in the infrastructure engineering industry. The need to develop long-term strategic asset management plans that are resilient to future needs while ensuring efficient and robust service delivery is becoming significantly important. Key challenges currently faced by the infrastructure industry worldwide include obsolescence, growing demands, climate change, increased vulnerability, demand for multi-functionality and growing interdependencies between different asset types. With the recent changes in the economic, social and environmental scenarios, there is increasing pressure to develop robust, flexible and multifunctional asset management solutions that not only suit the needs of the present but also ensure that the infrastructure will be safe, secure and resilient whatever the future may hold.

The proposed asset management framework will enable strategic decision makers to evaluate the resilience potential of the proposed asset management solutions in light of FCs with varying socioeconomic and environmental patterns. This paper therefore provides a methodology and principles that can be used to create a bespoke tool that can be tailored to suit the clients' and stakeholder's needs and priorities, thereby making it more robust and flexible.

\section{Acknowledgements}

The authors would like to acknowledge the University of Birmingham and Amey PLC, which collectively funded this project. The authors wish to also acknowledge the EPSRC, who funded Dr Hunt under the current Liveable Cities Programme Grant (EP/J017698).

\section{REFERENCES}

Armitt J (2013) The Armitt Review - An Independent Review of Long Term Infrastructure Planning Commissioned for Labour's Policy Review. See http://www.armittreview.org/ (accessed 13/12/2013).
Benton M, Bradford J, Cleave BV and Willway T (2005) Highways Asset Management Procedures - Guidance on the Requirements for the Production of Highways Asset Management Plans and a Simple Valuation Methodology - PPR/INN/036/5. Transport Research Laboratory (TRL), Crowthorne.

Bernhardt KLS, Loehr JE and Huaco D (2003) Asset management framework for geotechnical infrastructure. Journal of Infrastructure Systems 9(3): 107-116.

Bissell JJ (2010) Resilience of UK Infrastructure. Post note 362, Parliamentary Office of Science and Technology (POST), London, pp. 1-4.

Boyko CT, Gaterell MR, Barber ARG et al. (2012) Benchmarking sustainability in cities: the role of indicators and future scenarios. Global Environmental Change 22(1): 245-254.

Bullock N (2002) Building the Post-war World: Modern Architecture and Reconstruction in Britain. Routledge, London, UK.

Cabinet Office (2011) Keeping the Country Running: Natural Hazards and Infrastructure: A Guide to Improving the Resilience of Critical Infrastructure and Essential Services [Report]. Cabinet Office, London, UK.

Clay CRI (2001) Managing Geotechnical Risk: Improving Productivity in UK Building and Construction. Thomas Telford (Institution of Civil Engineers), London, UK, 80 pp.

County Surveyors Society (CSS) (2004) Framework for Highway Asset Management. County Surveyors Society, London, UK.

Federal Highway Administration (FHWA) (2009) Management Systems: Driving Performance - A Glance at Data-Driven Decision Making Practices. FHWA, Washington, DC, USA.

HM Treasury (2010a) National Infrastructure Plan 2010. HM Treasury, London, UK.

HM Treasury (2010b) Infrastructure Cost Review: Main Report. HM Treasury, London, UK, pp. 1-36.

HM Treasury (2011) Autumn Statement 2011. HM Treasury, London, UK.

HM Treasury (2012) Infrastructure Cost Review: Annual Report 2011-12. HM Treasury, London, UK.

Highways Agency (2013) Highways Agency Annual Report and Accounts 2012-13. The Stationery Office, London, UK.

Hudson S, Cormie D, Tufton E and Inglis S (2012) Engineering resilient infrastructure. Proceedings of the ICE - Civil Engineering 165(6): 5-12.

Hunt DVL, Lombardi DR, Atkinson S et al. (2012) Scenario archetypes: converging rather than diverging themes. Sustainability 4(4): 740-772.

Lee V (2012) Thoughts.arup.com. Sandy's Lessons for Resilience Planning. See http://thoughts.arup.com/post/details/252/ sandys-lessons-for-resilience-planning (accessed 30/11/2013).

Lombardi DR, Leach JM, Rogers CDF et al. (2012) Designing Resilient Cities: A Guide to Good Practice. IHS BRE Press, Bracknell, UK.

Management Consultancies Association (2013) Building Blocks How Britain Can Get Infrastructure Right. Management Consultancies Association, London, UK. 
Organisation for Economic Co-operation and Development (OECD) (2001) Asset Management for the Roads Sector. OECD Publications, Paris, France.

Publically Available Standard (PAS) 55 (2008) Optimal Management of Physical Assets. British Standards Institution (BSI), London, UK.

Rogers CDF, Lombardi DR, Leach JM and Cooper RFD (2012) The urban futures methodology applied to urban regeneration. Proceedings of the ICE - Engineering Sustainability $\mathbf{1 6 5}$ : 5-20.

The Institution of Civil Engineers (ICE) (2009) The State of the Nation - Defending Critical Infrastructure. The Institution of Civil Engineers (ICE), London, UK, pp. 1-16.
The Institution of Civil Engineers (ICE) (2013) Conference 'UK Transport - Engine of Growth', London, UK.

Theiam.org (2012) What is Asset Management? IAM - The Institute of Asset Management. See http://theiam.org/what-isasset-management (accessed 15/11/2013).

United Nations, Department of Economic and Social Affairs, Population Division (2013) World Population Prospects: The 2012 Revision, Key Findings and Advance Tables. Working Paper No. ESA/P/WP.227. United Nations, New York, USA. Walsh I (2011) ICE Manual of Asset Management. Institute of Civil Engineers (ICE), London, UK.

Wolfe T (1981) From Bauhaus to Our House. Bantam Books, New York, USA.

\section{WHAT DO YOU THINK?}

To discuss this paper, please submit up to 500 words to the editor at journals@ice.org.uk. Your contribution will be forwarded to the author(s) for a reply and, if considered appropriate by the editorial panel, will be published as a discussion in a future issue of the journal. 